\title{
5-week suspension training program increase physical performance of youth judokas: a pilot study Un programa de entrenamiento de suspensión de 5 semanas incrementa el rendimiento físico en jóvenes judocas: un estudio piloto \\ *Yessenia Norambuena, *Lorena Winkler, *Rocío Guevara, *Pamela Lavados, *Manuel Monrroy, **Rodrigo Ramírez- Campillo, $* * *$ Tomás Herrera-Valenzuela, ${ }^{*}$ Rubén Gajardo-Burgos \\ *Universidad Austral de Chile (Chile), **Universidad de Los Lagos (Chile), ***Universidad Santo Tomás (Chile)
}

\begin{abstract}
Introduction: Judo is a high-intensity sport, characterized by a series of acyclic movements that require high technical mastery during combat. It was previously shown that growth of components of physical function is related with an increased probability successful competitive performance. Suspension training is effective at improving components of physical function. Objective: Therefore, the aim of this study was to determine the changes in physical performance traits of youth judokas after a 5-week suspension-training programme. Methods: Ten judokas (age, $15.4 \pm 2.8 \mathrm{y}$ ) completed a 5-week suspension training routine into their normal training schedule. The difficulty and intensity of the exercises were increased each week. Before and after the intervention athletes were assessed in the single-leg horizontal jumping, Sorensen test, sit-and-reach, Y balance, prone instability and handgrip strength tests. Results: Significant improvements ( $<<.05$; Cohen d effect size e».2) were observed in the single-leg horizontal jumping (right leg: $137 \pm 23.3 \mathrm{vs}$ $164 \pm 22.0$; left leg: $131 \pm 24.1$ vs $169 \pm 26.5 \mathrm{~cm})$, Sorensen $(134 \pm 43.4$ vs $195 \pm 46.7 \mathrm{~s})$, sit-and-reach $(42.1 \pm 8.2 \mathrm{vs} 46.2 \pm 7.5 \mathrm{~cm})$, leg Y balance test (right leg: $91.3 \pm 6.6$ vs $101 \pm 7.6 \%$; left leg: $91.2 \pm 4.8$ vs $103 \pm 6.6 \%$ ) and arm Y balance test (right arm: $80.9 \pm 9.2$ vs $89.3 \pm 8.4$; left arm: $81.4 \pm 8.6$ vs $90.0 \pm 9.6 \%$ ) Conclusions: Lower-body muscle power, muscle endurance, flexibility, lower-body and upper-body balance physical performance traits were improved after a 5 -week training period in youth judokas that replaced a part of their regular judo training with a suspension training routine.
\end{abstract}

Key words: physical fitness; judo; sports injury; unstable surface training; plyometric exercise; combat sport; martial arts, maturity.

Resumen. Introducción: El judo es un deporte de alta intensidad, caracterizado por una serie de movimientos acíclicos con una alta maestría técnica durante el combate. Se ha demostrado previamente que el desarrollo de componentes de la función física se relaciona con una mayor probabilidad de rendimiento competitivo exitoso. El entrenamiento de suspensión es efectivo en mejorar los componentes de la función física. Objetivo: Determinar los cambios en el rendimiento físico en judocas jóvenes, después de un programa de entrenamiento de suspensión de 5 semanas. Método: Diez judocas (15.4 \pm 2.8 años de edad) completaron un programa de entrenamiento de suspensión de 5 semanas dentro de su programación normal de entrenamiento. La dificultad e intensidad de los ejercicios se incrementó cada semana. Antes y después de la intervención se evaluó un salto horizontal monopodal, test de Sorensen, sit and reach, Y balance test de miembros inferiores y superiores, test de inestabilidad en prono y fuerza prensil. Resultados: Mejoras significativas ( $<.05$; Cohen $\mathrm{d}$ effect size e».2) fueron encontradas en salto horizontal monopodal (derecha: $137 \pm 23.3$ vs $164 \pm 22.0$; izquierda: $131 \pm 24.1$ vs $169 \pm 26.5 \mathrm{~cm}$ ), test de Sorensen ( $134 \pm 43.4$ vs $195 \pm 46.7 \mathrm{~s})$, sit-and-reach $(42.1 \pm 8.2 \mathrm{vs} 46.2 \pm 7.5 \mathrm{~cm})$, Y balance test de miembros inferiores (derecha: 91.3 \pm 6.6 vs $101 \pm 7.6 \%$; izquierda: $91.2 \pm 4.8$ vs $103 \pm 6.6 \%$ ) and $Y$ balance test de miembros superiores (derecho: $80.9 \pm 9.2$ vs $89.3 \pm 8.4$; izquierdo: $81.4 \pm 8.6$ vs $90.0 \pm 9.6 \%$ ). Conclusiones: La potencia de miembros inferiores, resistencia muscular, flexibilidad y balance de miembros inferiores y superiores mejoró después de un programa de entrenamiento de suspensión de 5 semanas en judocas jóvenes.

Palabras claves: aptitud física; judo; lesión deportiva; entrenamiento en superficie inestable; ejercicio pliométrico; deportes de combate; artes marciales, madurez.

\section{Introduction}

Judo is a physically demanding sport among youths (Demorest, Koutures, \& Council On Sports and Fitness, 2016), posing a great tax on balance, neuromuscular control, flexibility and stability (Franchini, Del Vecchio, Matsushigue, \& Artioli, 2011; Hurel, Guillen, Gutiérrez, Sanabria, Formoso, $\&$ Rosero, 2019). The coordinated interaction of these components is fundamental to obtain adequate athletic performance (Detanico, Dal Pupo, Franchini, \& Giovana dos Santos, 2012). In addition, adequate levels of strength, endurance and power of the lower-body muscles are required in order to perform attack and defensive movements on an unstable support base, destabilize opponents, and increase the chances to win a match (Vidal, Franzói de Moraes, Lopes de Moraes, Del Conty, Vidal, \& Franchini 2011).

Various strength training programs have been applied in judo athletes, improving maximum isometric strength

Fecha recepción: 30-03-20. Fecha de aceptación: 28-05-20 Rubén Gajardo Burgos

ruben.gajardo@docentes.uach.cl
(Franchini, Takito, \& Kiss, 2000) endurance strength (Franchini, Branco, Agostinho, Calmet, \& Candau, 2015), general dynamic maximum strength (Stojanovic, Ostojic, Patrik, \& Milosevic, 2009), and in the execution of specific techniques (Blais \& Trilles, 2006).

Better physical performance from an adequate multicomponent training approach (e.g., technical, tactical, psychological training), is related to successful competitive performance (Kuvacic, Krstulovic, \& Caput, 2017). Several training approaches have been suggested to improve physical performance such as endurance training (Hurel et al., 2019), plyometric training (Ramirez-Campillo, SanchezSanchez, Romero-Moraleda, Yanci, Garcia-Hermoso, \& Clemente, 2020), and core training (Flores-Leon, Soto, Araneda, Guzman-Venegas, \& Berral de la Rosa, 2018), among others. However, most of these studies have focused on training programs aimed at improving only one or two physical performance traits, while a broader spectrum of physical performance variables are of consideration in judo. In addition, previous studies usually implemented long-term (time consuming) interventions that may be unrealistic in practical setting. 
Training programs on unstable surfaces may aid to develop more than one physical performance trait relevant for judo, with meaningful effects in a relatively short period. For example, among unstable training devices, suspension training offer the highest activation of core stabilizing muscles (Byrne, Bishop, Caines, Crane, Feaver, \& Pearcey, 2014; Fong, Tam, Macfarlane, Ng, Bae, Chan, \& Guo, 2015; Mok, Yeung, Cho, Hui, Liu, \& Pang, 2015), key to judo athletes. In addition, motor control, endurance, strength and muscle power (Bettendorf, 2010) may be significantly improved through suspension training, physical performance traits that may aid judo athletes to perform better and reduce their risk to sustain injuries. However, to the best of the author's knowledge, the effects of suspension training on judo athletes have not been investigated.

Therefore, the aim of this study was to determine the changes in physical performance traits of youth judokas after a 5-week suspension-training programme. We hypothesize that 5-week of suspension training would improve physical performance in judokas.

\section{Material and methods}

\section{Participants}

Youth judokas ( 8 females; 2 males; age, $15.4 \pm 2.8$ y; height, $154 \pm 10.3 \mathrm{~cm}$; body mass, $57.6 \pm 12.5 \mathrm{~kg}$; body mass index, $24.0 \pm 3.1 \mathrm{~kg} . \mathrm{m}^{-2}$; weekly training time, $7.6 \pm 1.8$ hours) participated in this study. Athletes were part of a High-Performance Training Centre, participating at international level competition. The Ethical Committee of the Valdivia Health Service (approval number 383-2014) approved the study and all procedures described in this study meet the requirements established in the last version of the declaration of Helsinki. Athletes were previously informed about the benefits and risks of the study and once accepted they signed an informed consent. If the athlete was under age, the parents/caregivers as well as the athlete signed an informed consent, and the athlete give their assent. To be included, athletes needed i) to be selected to integrate the High-Performance Training Centre, ii) a competition experience e» 2 years, iii) to be free of injuries at the time of enrolment and during the 4 weeks before enrolment, iv) a training attendance e» $80 \%$.

Athletes regularly attend judo-training sessions. Specific judo training was 5 session per week, each session of 100 min long and was composed by technical and tactical exercises. During the first $30 \mathrm{~min}$ the athletes started the session with specific warm-up (i.e., «ukemis» and «kumikata»), followed by $30 \mathrm{~min}$ of specific exercises (i.e., «uchi-komi» and «nage-komi»). The principal part, which lasted $30 \mathrm{~min}$, was composed by «randori». During the last 10-15 min, the athletes conducted static flexibility exercises.

\section{Procedures and measures}

Testing was performed in one session, both before and after the intervention, always following the same protocol, order of testing, same instructions, and by an experienced evaluator, blinded for the purposes of the study. All the variables were measured during the competitive period.

Single-leg horizontal jumping. To assess muscle power of the lower-limbs, the jump test was conducted as previously suggested (Swearingen et al., 2011), using a tape measure added to the floor, with a precision of $0.1 \mathrm{~cm}$.

Sorensen test. To assess the endurance of lumbar extensors muscles, the test was conducted as previously recommended (Demoulin, Vanderthommen, Duysens, \& Crielaard, 2006).

Sit-and-reach test. To assess lumbar spine and hamstring flexibility, the test was conducted as previously recommended (Ramirez-Campillo et al., 2015).

The Y balance test. To assess lower-body and upperbody balance, the test was applied as previously suggested (Gorman, Butler, Rauh, Kiesel, \& Plisky, 2012; Plisky, Gorman, Butler, Kiesel, Underwood, \& Elkins, 2009; Plisky, Rauh, Kaminski, \& Underwood, 2006).

Prone instability test. To assess neuromuscular control by positive or negative control of the lumbar-pelvic stabilizing muscles, the test was performed as previously described (Storheim, Bo, Pederstad, \& Jahnsen, 2002), using validated equipment (Stabilizer Pressure Bio-feedback, Chattanooga Group, 4717 Adams Road, Hixson TN, USA).

Grip strength. The test was conducted using validated equipment (JAMAR Dynamometer, PC 5030 J1, Sammons Preston Rolyan, USA), following previous recommendations (Fess, 1992).

\section{Training program}

The suspension-training program was composed of diverse TRX ${ }^{\circledR}$ suspension trainer exercises (TRX ${ }^{\circledR}$ suspension trainer, 755 Sansome Street, San Francisco, CA, USA). The suspension-training program (Table 1) was applied during 5 weeks, three times per week, before to each training session, with an emphasis on movement quality (i.e., technique), replacing a part of the athlete's normal judo training routine, following previous recommendations (Bettendorf, 2010; Byrne et al., 2014; Fong et al., 2015; Imai, Kaneoka, Okubo, Shiina, Tatsumura, Izumi, \& Shiraki, 2010; Mok et al., 2015; Myer, Ford, Brent, \& Hewett, 2006).

All suspension-training sessions begun with a 5-7 minutes period of continuous low-intensity jogging warmup. Then athletes perform two sets of 30 seconds of static stretching exercises using the suspension gear. The stretching drills were repeated at the end of each suspension-training sessions. The difficulty of the drills and the volume was progressively increased during the 5 weeks of training. A qualified trainer and two assistants, providing verbal feedback and visual demonstration of each movement, supervised all sessions. In addition, a DVD was given to the athletes before the start of the intervention programme with explicative videos of how to perform each exercise. Moreover, at the start of each weekly training session time was devoted to explain how to use the suspension gear and how to perform the exercises, assuring that the athletes performed these correctly. A typical suspension-training session last $\sim 20$ minutes.

\section{Statistical Analysis}

Data are presented as group mean values \pm standard deviations, aside from absolute frequency values for qualitative variables. After data normality assumption was verified with the Shapiro-Wilk test, the Student's t test for 
related samples was used to compare dependent variables values between before and after the application of the independent variable (experimental treatment). Effect sizes were determined by calculating Cohen's d values (Cohen, 1988). Cohen's d describes the effectiveness of a treatment and determines whether a statistically significant difference is a difference of practical concern. Cohen's d values are classified as small ( $\mathrm{d} d \gg 0.49)$, medium $(\mathrm{d}=0.50$ to $\mathrm{d} \gg 0.79)$, and large effects (d e» 0.8) (Cohen, 1988). Statistical analyses were carried out with STATISTICA statistical package (Version 8.0; StatSoft, Inc, Tulsa), with á set at 5\%.

\section{Results}

Significant improvements were observed in the singleleg horizontal jumping test for both legs $(\mathrm{p}<0.01$; $d=1.1$ $1.4)$, the Sorensen test $(\mathrm{p}<0.01 ; \mathrm{d}=1.2)$, the sit-and-reach test $(\mathrm{p}<0.01 ; \mathrm{d}=0.5)$, and the $\mathrm{Y}$ balance test for the right leg $(\mathrm{p}<0.01 ; \mathrm{d}=1.2)$, left leg $(\mathrm{p}<0.01 ; \mathrm{d}=1.8)$, right $\operatorname{arm}(\mathrm{p}<0.05 ; \mathrm{d}$ $=0.9)$ and left $\operatorname{arm}(\mathrm{p}<0.05 ; \mathrm{d}=0.9)($ Table 2$)$. Moreover, when absolute pre-post intervention value changes were considered, in the single-leg horizontal jumping test for both legs, the Sorensen test, the sit-and-reach test, and the Y balance test for both legs, improvements were observed in 10 out of 10 participants. In addition, in the $\mathrm{Y}$ balance test for both arms improvements were noted in 7 out of 10 participants.

Grip strength (Right: Pre $30.3 \pm 9.2$, Post 30.1 \pm 9.6 ; Left: Pre 27.9 \pm 8.2, Post $28.9 \pm 9.9 ; \mathrm{d}=0.0)$ ) (Table 2 ) and the prone instability test performance (Pre: 3 positive control vs 7

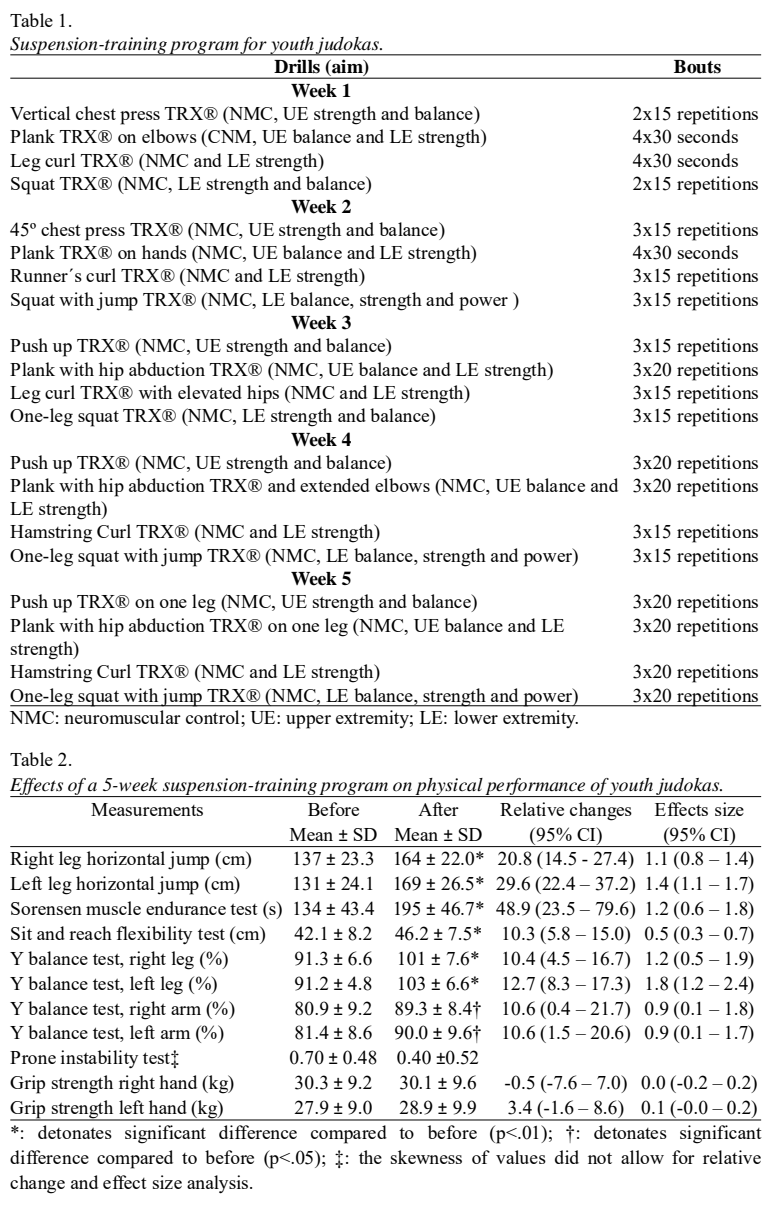

negative control; Post: 6 positive control vs 4 negative control) were not modified after the intervention period ( $\mathrm{p}>0.05)$.

\section{Discussion}

The aim of this study was to determine the changes in physical performance traits of youth judokas after a 5-week suspension-training programme. Main results indicate that most (lower-body muscle power; muscle endurance; flexibility; lower-body and upper-body balance) physical performance traits were improved after the intervention.

Lower-body muscle power (i.e. jumping) was improved after the 5 weeks of intervention. This physical capacity has an important relationship with competitive performance. Indeed, the improvement in muscle power may be important when judo techniques are applied in a short period of time (explosive performance). Such actions are decisive for competition success, and jumping performance is related to competitive success (Franchini et al., 2011). Kons et al, (2018) found that females judokas with greater leg power showed greater effectiveness time during a combat. Previous studies involving plyometric drills (as in our intervention) observed an improvement in lower-body muscle power after interventions (Herrera-Valenzuela et al., 2016; Moran, Sandercock, Ramirez-Campillo, Meylan, Collison, \& Parry, 2017; Ramirez-Campillo, et al., 2020; Rosas et al., 2016). On the contrary, changes in muscle power due to maturity-only are unlikely in highly-trained youth combat-sport athletes after a 5-week period (Herrera-Valenzuela et al., 2016). Taking together, changes in lower-limb muscle power can be hypothesized in youth judo athletes after a 5-week suspension training program such as the one applied in this pilot study.

The benefits of suspension-training may be related to the increase in mechanoreceptor stimuli (Myer et al., 2006), provided by this type of exercise, which is based on closed kinetic chain exercises, thus increasing the axial joint load, the perception of joint movement, and the contraction of stabilizing muscles (Borreani, Calatayud, Colado, Tella, Moya-Najero, Martin, \& Rogers, 2015; Cugliari \& Boccia, 2017; Harris, Ruffin, Brewer, \& Ortiz, 2017).

Regarding spinal extensor muscles resistance, this trait was increased after the intervention. Muscle endurance is an important characteristic for judo athletes, as they must apply powerful techniques repeatedly during combats, with a work:pause relationship 20sec:10sec (Miarka, Ferreira, Boscolo, Calmet, \& Franchini, 2010). Differences in resistance to force, to perform the traction and push movements more effectively, can influence and be potential predictors of judo performance. The increase may be related with the effect of suspension-training on a greater trunk stability demand during drills execution, inducing greater activation of lumbar-pelvic stabilizing muscles (Imai et al., 2010).

Current results also indicate an improvement in flexibility performance after the intervention. Given the relevance of adequate flexibility to reduce injury risk in youth population (Useros \& Campos, 2011), current results are of paramount importance in youth judo athletes. Previous studies also have found improvements in flexibility in youth athletes after application of others strength-training methods (Ramirez- 
Campillo et al., 2015). Eccentric contractions were used in most of the exercises during the intervention, which might have induced sarcomerogenesis (Zollner, Abilez, Bol, \& Kuhl, 2012), increasing muscle length and therefore flexibility (O'Sullivan, McAuliffe, \& Deburca, 2012). Although most of the flexibility studies in judo have used the seat and reach test (Franchini et al., 2011), because of its ease of application, it is not a specific test for judo athletes. Additionally, the results obtained have found values close to the population average (Schwartz, Takito, Del Vecchio, Antonietti, \& Franchini, 2015).

To the best of our knowledge, this is the first study that analyzed the effect of suspension training during youth judokas preparation on balance performance. Current results help to expand the limited knowledge available about this topic. Our results show that the youth athletes achieves a statistically significant increase in all balance performance indices, with a small but meaningful effect size. Improvement in balance has been observed in previous interventions that incorporate other strength training modalities in youth athletes (Myer et al., 2006). Improvements usually taking 5-6 weeks to occur (Zech, Abilez, Bol, \& Kuhl, 2010), including strength training interventions with youth athletes (Behm et al., 2017; Granacher et al., 2016; Granacher, Prieske, Majewski, Busch, \& Muehlbauer, 2015; Myer et al., 2006). Because balance improvement may not only result in an increased athletic performance but also in reduced lower extremity injury risk (Zech et al., 2010), current results reinforce the value of balance-training, in this case as an potentially effective strategy to reduce injury risk in young athletes. Of note, the significant balance performance change may be related with the fact that athletes incorporated an integrated training protocol (i.e., multicomponent training) that may be the most effective training model (Brown, Palmieri-Smith, \& McLean, 2014; Herrera-Valenzuela et al., 2016). This observation may reinforce the necessity to include combination of suspension training during regular judo training to induce optimum training adaptations for both upper and lower extremity balance performance. The improvement in balance performance may be related to improved cocontraction of lower extremity muscles (Lloyd, 2001) or changes in proprioception and neuromuscular control (Hewett, Paterno, \& Myer, 2002).

The prone instability test performance was not significantly changed after the intervention period. It may be that this test was not well suited for this population. In this sense, it have been suggested (Mills, Taunton, \& Mills, 2005) that the test is not a useful tool for detection of performance changes in athletes. Similarly, although grip strength is a widely used test to assess combat-sport athletes performance (Ache, Wentz, Külkamp, Mattos, Goethel, \& Borges, 2012; Vidal et al., 2011), current results suggest that grip strength was not significantly changed after the intervention period. Our results agree with the study by Fukuda et al. (2013), who applied a program of physical, technical and tactical training, during a 4-week training camp for youth judo athletes, without finding improvements in the handgrip. The lack of improvement may be related with the lack of specificity between the test and the muscle groups being taxed during suspension-training drills, including lack of duration of contraction specificity and intensity specificity (Hill, \&
Leiszler, 2011), for example, in a study conducted with youth judo athletes, they trained 3 to 4 sets of $6-8$ rep at $80 \%$ for the main muscle groups, 2 to 3 times a week, for 4 months, significantly increasing the handgrip (Franchini et al., 2000), in the same way, a studio conducted by Franchini et al. (2015), with judo athletes, found improvements in the handgrip with linear periodization and undulating periodization. In this sense, grip strength was not trained at a high intensity (i.e., maximum repetitions), instead a moderate-low intensity was used for relative extended periods of time. Therefore, future studies may consider the use of test more sensitives to the potential adaptations induced by suspension training, such as handgrip endurance. In this sense, unlike maximal handgrip strength (i.e., single repetition, maximal intensity, during $<5$ seconds), judo combats usually requires handgrips between 11 to 21 seconds (Miarka et al., 2010). This is supported by a study (Bonitch \& Almeida, 2014) who proposed that handgrip endurance (e.g., resistance) maybe more relevant than maximum strength for judokas, which also may help to explain why the maximum handgrip strength between judoka and non-judoka subjects was not significant different (Ache et al., 2012).

\section{Conclusions}

Suspension training can be a tool for coaches and strength and conditioning professionals to improve fitness. Additionally, suspension training can be a practical tool to maintain proper training, during sports tours and trips, when there is no possibility of accessing training centers with specific equipment.

A possible limitation of the present study was the small size of the sample and the absence of a control group. However, the sample corresponds to all the athletes of the high performance center. Additionally, establishing a control group is difficult in athletes during the competitive period.

\section{References}

Ache Dias, J., Wentz, M., Külkamp, W., Mattos, D., Goethel, M., \& Borges Júnior, N. (2012). Is the handgrip strength performance better in judokas than in non-judokas? Science \& Sports, 27(3), e9-e14. Recuperado de http:// www.sciencedirect.com/science/article/pii/ S0765159711001754. doi:https://doi.org/10.1016/ j.scispo.2011.10.005

Behm, D. G., Young, J. D., Whitten, J. H. D., Reid, J. C., Quigley, P. J., Low, J., . . Granacher, U. (2017). Effectiveness of traditional strength vs. power training on muscle strength, power and speed with youth: a systematic review and meta-analysis. Front Physiol, 8(423). Recuperado de http:// journal.frontiersin.org/article/10.3389/fphys.2017.00423. doi:10.3389/fphys.2017.00423

Bettendorf, B. (2010). TRX Suspension Training Bodyweight Exercise: Scientific Foundations and Practical Applications. San Francisco: Fitness Anywhere Inc.

Blais, L., \& Trilles, F. (2006). The progress achieved by judokas after strength training with a judo-specific machine. J Sports Sci Med, 5(CSSI), 132-135. Recuperado de https:// www.ncbi.nlm.nih.gov/pubmed/24357985.

Bonitch, J., \&Almeida, F. (2014). The isometric grip force in judo. 
Rev Artes Marciales Asiat, 9(1), 9-19.

Borreani, S., Calatayud, J., Colado, J. C., Tella, V., Moya-Najera, D., Martin, F., \& Rogers, M. E. (2015). Shoulder muscle activation during stable and suspended push-ups at different heights in healthy subjects. Physical Therapy in Sport, 16(3), 248-254. doi:10.1016/j.ptsp.2014.12.004

Brown, T. N., Palmieri-Smith, R. M., \& McLean, S. G. (2014). Comparative adaptations of lower limb biomechanics during unilateral and bilateral landings after different neuromuscularbased ACL injury prevention protocols. J Strength Cond Res, 28(10), 2859-2871. Recuperado de http:// www.ncbi.nlm.nih.gov/pubmed/24714537. doi:10.1519/ JSC.0000000000000472

Byrne, J. M., Bishop, N. S., Caines, A. M., Crane, K. A., Feaver,A. M., \& Pearcey, G. E. (2014). Effect of using a suspension training system on muscle activation during the performance of a front plank exercise. J Strength Cond Res, 28(11), 3049-3055. Recuperado de http://www.ncbi.nlm.nih.gov/ pubmed/24796979. doi:10.1519/JSC.0000000000000510

Cohen, J. (1988). Statistical Power Analysis for the Behavioral Sciences (2nd ed.). Hillsdale, N.J. : Lawrence Erlbaum.

Cugliari, G., \& Boccia, G. (2017). Core Muscle Activation in Suspension Training Exercises. J Hum Kinet, 56, 61-71. doi:10.1515/hukin-2017-0023

Demorest, R.A., Koutures, C., \& Council On Sports, M., \& Fitness. (2016). Youth Participation and Injury Risk in Martial Arts. Pediatrics, 138(6). Recuperado de http:// www.ncbi.nlm.nih.gov/pubmed/27940732. doi:10.1542/ peds.2016-3022

Demoulin, C., Vanderthommen, M., Duysens, C., \& Crielaard, J. M. (2006). Spinal muscle evaluation using the Sorensen test: a critical appraisal of the literature. Joint Bone Spine, 73(1), 43-50. doi:10.1016/j.jbspin.2004.08.002

Detanico, D., Dal Pupo, J., Franchini, E., \& Giovana dos Santos, S. (2012). Relationship of aerobic and neuromuscular indexes with specific actions in judo. Science \& Sports, 27(1), 16-22. Recuperado dehttp://www.sciencedirect.com/science/article/ pii/S076515971100013X. doi:https://doi.org/10.1016/ j.scispo.2011.01.010

Fess, E. (1992). Clinical Assessment Recommendations. Chicago: American Society of Hand Therapists.

Flores-Leon, A. F., Soto, V., Araneda, O. F., Guzman-Venegas, R., \& Berral de la Rosa, F. J. (2018). Muscle activity of the Lumbopelvic-hip complex in three isometric exercises using TRX ${ }^{\circledR}$ rip trainer ${ }^{\mathrm{TM}}$ (Actividad muscular del complejo Lumbo-Pelvis-Cadera en tres ejercicios isométricos usando TRX ${ }^{\circledR}$ rip trainer $^{\mathrm{TM}}$ ). 2018(35), 5. Recuperado de https://recyt.fecyt.es/ index.php/retos/article/view/63922.

Fong, S. S., Tam, Y.T., Macfarlane, D. J., Ng, S. S., Bae, Y.H., Chan, E. W., \& Guo, X. (2015). Core Muscle Activity during TRX Suspension Exercises with and without Kinesiology Taping in Adults with Chronic Low Back Pain: Implications for Rehabilitation. Evid Based ComplementAlternat Med, 2015, 910168. Recuperado de http://www.ncbi.nlm.nih.gov/ pubmed/26185520. doi:10.1155/2015/910168

Franchini, E., Branco, B. M., Agostinho, M. F., Calmet, M., \& Candau, R. (2015). Influence of linear and undulating strength periodization on physical fitness, physiological, and performance responses to simulated judo matches. J Strength Cond Res, 29(2), 358-367. Recuperado de https:// www.ncbi.nlm.nih.gov/pubmed/24662235. doi:10.1519/ JSC.0000000000000460
Franchini, E., Del Vecchio, F. B., Matsushigue, K.A., \&Artioli, G. G. (2011). Physiological profiles of elite judo athletes. Sports Med, 41(2), 147-166. Recuperado de https:// www.ncbi.nlm.nih.gov/pubmed/21244106. doi:10.2165/ 11538580-000000000-00000

Franchini,E., Takito, M.Y., \& Kiss, M.A.P.D. (2000). Somatotipo, composição corporal e força isométrica em diferentes períodos do treinamento em atletas de judô juvenis. Treinamento Desportivo, 5(2).

Fukuda, D. H., Stout, J. R., Kendall, K. L., Smith,A. E., Wray, M. E., \& Hetrick, R. P. (2013). The effects of tournament preparation on anthropometric and sport-specific performance measures in youth judo athletes. J Strength Cond Res, 27(2),331-339. Recuperado de https://www.ncbi.nlm.nih.gov/ pubmed/22476167. doi:10.1519/JSC.0b013e31825423b3

Gorman, P. P., Butler, R. J., Rauh, M. J., Kiesel, K., \& Plisky, P. J. (2012). Differences in dynamic balance scores in one sport versus multiple sport high school athletes. Int J Sports Phys Ther, 7(2), 148-153. Recuperado de http:// www.ncbi.nlm.nih.gov/pubmed/22530189.

Granacher, U., Lesinski, M., Busch, D., Muehlbauer, T., Prieske, O., Puta, C., . . Behm, D. G. (2016). Effects of resistance training in youth athletes on muscular fitness and athletic performance: a conceptual model for long-term athlete development. Front Physiol, 7, 164. Recuperado de http:// www.ncbi.nlm.nih.gov/pubmed/27242538. doi:10.3389/ fphys.2016.00164

Granacher,U., Prieske, O., Majewski, M., Busch,D., \& Muehlbauer, T. (2015). The Role of Instability with Plyometric Training in Sub-elite Adolescent Soccer Players. Int J Sports Med, 36(5), 386-394. Recuperado de http://www.ncbi.nlm.nih.gov/ pubmed/25665004. doi:10.1055/s-0034-1395519

Harris, S., Ruffin, E., Brewer, W., \& Ortiz, A. (2017). Muscle activation patterns during suspension training exercises. Int J Sports Phys Ther, 12(1), 42-52.

Herrera-Valenzuela, T., Valdés-Badilla, P., Franchini, E., Ferreira da Silva Santos, J., Ramirez-Campillo, R., Garcia-Hermoso, A., ... Castañeda-Gomez, J.(2016). Effects of multi-component training on the physical fitness of young taekwondo athletes. Ido Movement for Culture. Journal of Martials Arts Anthropology, 16(4), 31-37.

Hewett, T. E., Paterno, M. V., \& Myer, G. D. (2002). Strategies for enhancing proprioception and neuromuscular control of the knee. Clin Orthop Relat Res(402), 76-94. Recuperado de http:/ / w w w. n c bi.n $1 \mathrm{~m}$. n i h. g o v/ e n t r e z/ quary.fogi?cand Retrieve\&db-PubMed\&dopt=Citation\&list uids=12218474.

Hill, J., \& Leiszler, M. (2011). Review and role of plyometrics and core rehabilitation in competitive sport. Curr Sports Med Rep, 10(6), 345-351. Recuperado de http:// www.ncbi.nlm.nih.gov/pubmed/22071395. doi:10.1249/ JSR.0b013e31823b3b94

Hurel Tola, O. E., Guillen Pereira, L., Gutierrez Cruz, M., Sanabria Navarro, J. R., Formoso Mieres, A. A., \& Rosero Duque, M. F. (2019). Sistema de ejercicios específicos dirigidos al mejoramiento de la resistencia específica en la ejecución de la técnica de judo ippon seoi nage. 2019(37), 11. Recuperado de https://recyt.fecyt.es/index.php/retos/article/view/70924.

Imai, A., Kaneoka, K., Okubo, Y., Shiina, I., Tatsumura, M., Izumi, S., \& Shiraki, H. (2010). Trunk muscle activity during lumbar stabilization exercises on both a stable and unstable surface. J Orthop Sports Phys Ther, 40(6), 369-375. Recuperado de http://www.ncbi.nlm.nih.gov/pubmed/20511695. doi:10.2519/ 
jospt.2010.3211

Kons, R. L., Dal Pupo, J., Ache-Dias, J., \& Detanico, D. (2018). Female Judo Athletes' Physical Test Performances Are Unrelated to Technical-Tactical Competition Skills. Percept Mot Skills, 125(4), 802-816. Recuperado de https:// www.ncbi.nlm.nih.gov/pubmed/29788859. doi:10.1177/ 0031512518777586

Kuvacic, G., Krstulovic, S., \& Caput, P. D. (2017). Factors Determining Success in Youth Judokas. J Hum Kinet, 56, 207-217. Recuperado de https://www.ncbi.nlm.nih.gov/ pubmed/28469759. doi:10.1515/hukin-2017-0038

Lloyd, D. G. (2001). Rationale for training programs to reduce anterior cruciate ligament injuries in Australian football. J Orthop Sports Phys Ther, 31(11), 645-654; discussion 661. Recuperado de http://www.ncbi.nlm.nih.gov/entrez/ quary.cogi?cmd-Retrieve\&db-PubMed\&dope-Citation\&list_ uids=11720297. doi:10.2519/jospt.2001.31.11.645

Miarka, B., Ferreira, U., Boscolo, F., Calmet, M., \& Franchini, E. (2010). Technique and tactics in judo: a review. Rev Artes Marciales Asiat, 5(1), 91-112.

Mills, J. D., Taunton, J. E., \& Mills, W.A. (2005). The effect of a 10week training regimen on lumbo-pelvic stability and athletic performance in female athletes: Arandomized-controlled trial. Physical Therapy in Sport, 6(2), 60-66. Recuperado de http:/ /www.sciencedirect.com/science/article/pii/ S1466853X05000386. doi:https://doi.org/10.1016/ j.ptsp.2005.02.006

Mok, N.W., Yeung, E. W., Cho, J.C., Hui, S. C., Liu, K. C., \& Pang, C. H. (2015). Core muscle activity during suspension exercises. J Sci Med Sport, 18(2), 189-194. Recuperado de http://www.ncbi.nlm.nih.gov/pubmed/24556020. doi:10.1016/ j.jsams.2014.01.002

Moran, J. J., Sandercock, G. R., Ramirez-Campillo, R., Meylan, C. M., Collison, J.A., \& Parry, D. A. (2017).Age-related variation in male youth athletes' countermovement jump after plyometric training: A meta-analysis of controlled trials. J Strength Cond Res, 31(2), 552-565. Recuperado de http:// www.ncbi.nlm.nih.gov/pubmed/28129282. doi:10.1519/ JSC.0000000000001444

Myer, G D., Ford, K. R., Brent, J. L., \& Hewett, T. E. (2006). The effects of plyometric vs. dynamic stabilization and balance training on power, balance, and landing force in female athletes. J Strength Cond Res, 20(2), 345-353. Recuperado de http://www.ncbi.nlm.nih.gov/pubmed/16686562. doi:10.1519/ R-17955.1

O'Sullivan, K., McAuliffe, S., \& Deburca, N. (2012). The effects of eccentric training on lower limb flexibility: a systematic review. Br J Sports Med, 46(12), 838-845. Recuperado de http://www.ncbi.nlm.nih.gov/pubmed/22522590. doi:10.1136/ bjsports-2011-090835

Plisky, P. J., Gorman, P. P., Butler, R. J., Kiesel, K. B., Underwood, F. B., \& Elkins, B. (2009). The reliability of an instrumented device for measuring components of the star excursion balance test. NAm J Sports Phys Ther, 4(2), 92-99. Recuperado de http://www.ncbi.nlm.nih.gov/pubmed/21509114.

Plisky, P. J., Rauh, M. J., Kaminski, T. W., \& Underwood, F. B. (2006). Star Excursion Balance Test as a predictor of lower extremity injury in high school basketball players. J Orthop Sports Phys Ther, 36(12), 911-919. Recuperado de http:// www.ncbi.nlm.nih.gov/pubmed/17193868. doi:10.2519/ jospt.2006.2244

Ramirez-Campillo, R., Meylan, C.M.,Alvarez-Lepin, C., Henriquez-
Olguin, C., Martinez, C., Andrade, D. C., . . . Izquierdo, M. (2015). The effects of interday rest on adaptation to 6 weeks of plyometric training in young soccer players. J Strength CondRes, 29(4), 972-979. doi:10.1519/jsc.0000000000000283

Ramirez-Campillo, R., Sanchez-Sanchez, J., Romero-Moraleda, B., Yanci, J., Garcia-Hermoso, A., \& Manuel Clemente, F. (2020). Effects of plyometric jump training in female soccer player's vertical jump height: A systematic review with metaanalysis. J Sports Sci, 1-13. Recuperado de https:// www.ncbi.nlm.nih.gov/pubmed/32255389. doi:10.1080/ 02640414.2020.1745503

Rosas, F., Ramirez-Campillo, R., Diaz, D.,Abad-Colil, F., MartinezSalazar, C., Caniuqueo, A., . . Izquierdo, M. (2016). Jump Training in Youth Soccer Players: Effects of Haltere Type Handheld Loading. Int J Sports Med, 37(13), 1060-1065. Recuperado de http://www.ncbi.nlm.nih.gov/pubmed/ 27557406. doi:10.1055/s-0042-111046

Schwartz, J., Takito, M. Y., Del Vecchio, F. B., Antonietti, L. S., \& Franchini, E. (2015). Health-related physical fitness in martial arts and combat sports practitioners. Sport Sciences for Health, 11(2), 171-180. Recuperado de https://doi.org/10.1007/ s11332-015-0220-6. doi:10.1007/s11332-015-0220-6

Stojanovic, B., Ostojic, S., Patrik, D., \& Milosevic, Z. (2009). Physiological adaptations to 8-week precompetitive training period in elite female judokas. Medicina dello Sport, 62(4), 415-24.

Storheim, K., Bo, K., Pederstad, O., \& Jahnsen, R. (2002). Intratester reproducibility of pressure biofeedback in measurement of transversus abdominis function. Physiother Res Int, 7(4), 239-249. Recuperado de http:// www.ncbi.nlm.nih.gov/pubmed/12528579.

Swearingen, J., Lawrence, E., Stevens, J., Jackson, C., Waggy, C., \& Davis, D. S. (2011). Correlation of single leg vertical jump, single leg hop for distance, and single leg hop for time. Physical Therapy in Sport, 12(4), 194-198. Recuperado de http://www.ncbi.nlm.nih.gov/pubmed/22085714. doi:10.1016/ j.ptsp.2011.06.001

Useros García, P., \& Campos Aranda, M. (2011). Estiramientos analíticos y stretching global activo en clases de educación física. Fisioterapia, 33(2), 70-78. Recuperado de http:// www.elsevier.es/en-revista-fisioterapia-146-articuloestiramientos-analiticos-stretching-global-activoS0211563811000265.doi:10.1016/j.ft.2011.02.003

Vidal Andreato, L., Franzói de Moraes, S. M., Lopes de Moraes Gomes, T., Del Conti Esteves, J. V., Vidal Andreato, T., \& Franchini, E. (2011). Estimated aerobic power, muscular strength and flexibility in elite Brazilian Jiu-Jitsu athletes. Science \& Sports, 26(6), 329-337. Recuperado de http:// www.sciencedirect.com/science/article/pii/ S0765159711000025. doi:https://doi.org/10.1016/ j.scispo.2010.12.015

Zech,A., Hubscher, M., Vogt, L., Banzer, W., Hansel, F., \& Pfeifer, K. (2010). Balance training for neuromuscular control and performance enhancement: a systematic review. J Athl Train, 45(4), 392-403. Recuperado de http://www.ncbi.nlm.nih.gov/ $\begin{array}{lllllll}\mathrm{e} & \mathrm{n} & \mathrm{t} & \mathrm{r} & \mathrm{e} & \mathrm{z} & \text { / }\end{array}$ quaryfogi?cmd-Retrieve\&db-PubMed\&dopt=Citation\&list uids=20617915. doi:10.4085/1062-6050-45.4.392

Zollner,A. M.,Abilez, O. J., Bol, M., \& Kuhl, E. (2012). Stretching skeletal muscle: chronic muscle lengthening through sarcomerogenesis. PLoS One, 7(10), e45661. Recuperado de http://www.ncbi.nlm.nih.gov/pubmed/23049683. doi:10.1371/ journal.pone. 0045661 